\title{
Correlates of fruit and vegetable intake among parents and adolescents: findings from the Family Life, Activity, Sun, Health, and Eating (FLASHE) study
}

\author{
Courtney A Parks ${ }^{1, *}$, Casey Blaser ${ }^{1}$, Teresa M Smith ${ }^{1}$, Eric E Calloway ${ }^{1}$, April Y Oh², \\ Laura A Dwyer ${ }^{2}$, Benmai Liu ${ }^{2}$, Linda C Nebeling ${ }^{2}$ and Amy L Yaroch ${ }^{1}$ \\ 'Gretchen Swanson Center for Nutrition, 8401 West Dodge Road, Suite 100, Omaha, NE 68114, USA: \\ ${ }^{2}$ Behavioral Research Program, National Cancer Institute, Rockville, MD, USA
}

Submitted 14 November 2017: Final revision received 13 February 2018: Accepted 2 March 2018: First published online 16 April 2018

\begin{abstract}
Objective: The present study aimed to examine the correlates of fruit and vegetable intake (FVI) separately among parents and their adolescents.

Design: Cross-sectional surveys.

Setting: Online survey.

Subjects: Parents and adolescents completed the Family Life, Activity, Sun, Health, and Eating (FLASHE) survey through the National Cancer Institute. The survey assessed daily intake frequencies of food/beverage groups, psychosocial, parenting and sociodemographic factors. Generalized linear models were run for both parents and adolescents, for a total of six models (three each): (i) sociodemographic characteristics; (ii) psychosocial factors; (iii) parent/ caregiver factors.

Results: Parent participants ( $n$ 1542) were predominantly 35-59 years old ( $86 \%$ ), female $(73 \%)$, non-Hispanic White $(71 \%)$ or non-Hispanic Black (17\%), with household income <\$US 100000 (79\%). Adolescents ( $n$ 805) were aged 12-14 years (50\%), non-Hispanic White (66\%) and non-Hispanic Black (15\%). Parents consumed 2.9 cups fruits and vegetables (F\&V) daily, while adolescents consumed $2 \cdot 2$ cups daily. Educational attainment (higher education had greater FVI) and sex (men consumed more than women; all $P<0.001$ ) were significant FVI predictors. Parents with greater autonomous and controlled motivation, selfefficacy and preferences for fruit reported higher FVI (all $P<0 \cdot 001$ ). Similarly, adolescents with greater autonomous and controlled motivation, self-efficacy and knowledge reported higher FVI (all $P<0.001$ ). Parenting factors of importance were co-deciding how many F\&V teens should have, rules, having F\&V in the home and cooking meals from scratch (all $P<0 \cdot 05$ ).

Conclusions: Findings suggest factors that impact FVI among parents and their adolescent(s), which highlight the importance of the role of parent behaviour and can inform tailored approaches for increasing FVI in various settings.
\end{abstract}

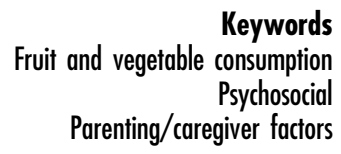

Obesity among adults and youth remains a public health concern $^{(1)}$. Potential negative consequences include poor health-related outcomes, including increased risk of CVD, type 2 diabetes and some types of cancer $^{(2)}$, economic $\operatorname{costs}^{(3,4)}$ and psychological impact ${ }^{(5)}$. A major factor contributing to obesity is an increase in overall energy intake $^{(6,7)}$, which is related to a greater consumption of energy-dense and nutrient-poor foods ${ }^{(8,9)}$ and poor dietary quality evidenced by a lack of fruit and vegetable intake $(\mathrm{FVI})^{(10,11)}$. Numerous studies have indicated an inverse association between FVI and development of obesity ${ }^{(12-14)}$. In addition, FVI has been related to prevention of a number of different cancers, above and beyond obesity prevalence $^{(15,16)}$. However, fewer than one-quarter of Americans (adults and youth) eat the recommended daily servings of fruits and vegetables $(\mathrm{F} \& \mathrm{~V})^{(17,18)}$.

Evidence suggests that individual, social and environmental factors explain much of the variation in healthy eating $^{(19,20)}$. Previous research indicates self-efficacy, social support, motivation, taste preferences and knowledge are correlates of FVI among adults ${ }^{(21,22)}$. Similar findings of individual correlates of FVI have been reported among adolescents $^{(23-25)}$. Beyond the individual, the importance of the home environment and family correlates of FVI have 
also been examined ${ }^{(24,26,27)}$. Parents influence their children's FVI through role modelling, home food availability, policies and parenting approaches, knowledge and other practices ${ }^{(27)}$. Although many studies have conducted interventions targeting the family unit in order to address obesity $^{(28,29)}$, and cohort studies have occurred among youth $^{(26,27)}$, the correlates of FVI among a national sample of adults and their adolescent offspring have yet to be explored. Given the multitude of parental influences on children's FVI and the fact that multilevel factors have not been explored in both parents and adolescents at a national level, the purpose of the present study was to examine the correlates of FVI separately among parents and their adolescent children.

\section{Methods}

\section{Study sample}

The National Cancer Institute conducted the Family Life, Activity, Sun, Health, and Eating Study (FLASHE) from April to October 2014. Parent-adolescent dyads were recruited to complete a screener through a consumer opinion panel with the intention to match the US population on key demographic characteristics for representativeness. Adult respondents were included if they were aged 18 years or older and were the legal guardian of an eligible adolescent (aged 12-17.5 years) who lived with them at least $50 \%$ of the time. Respondents were selected purposively to balance age, sex, location, income, household size and race/ethnicity. Eligible adolescents included those aged $12-17.5$ years and living with the panel member for at least $50 \%$ of the time. During the screening process, information on the eligible adolescents in the household was collected via a full household roster and one eligible adolescent was randomly selected until the quota for each age range (12-13, 14-15, 16-17 years) was full. Approximately one-third of adolescent participants were recruited in each of the three age ranges, evenly split by gender. Dyads were presented with two sets of surveys: a diet-focused survey and a physical activity-focused survey for the parents and adolescents. Respondents were provided a \$US 5 cash incentive for each completed survey or a \$US 10 incentive if they completed a survey during a 'bonus' data collection period designated to promote survey completion ${ }^{(30)}$. The overall study response rate was $29.4 \%$, and the FLASHE recruitment and response rates are described in depth elsewhere $^{(30)}$.

Although based on a non-probability sample, 'analysis weights' were created for the FLASHE sample by ranking the base weight (equal to 1) to the target population totals derived from the 2013 American Community Survey for the parent sample and the 2014 Current Population Survey (CPS) Annual Social and Economic Supplement for the adolescent sample on key demographics including gender, age, income, marital status, race/ethnicity, homeownership, work status and census region. Thus, the FLASHE sample has a similar distribution of demographics to the general population.

\section{FLASHE Dietary Screener}

The twenty-seven-item FLASHE Dietary Screener administered as part of the FLASHE diet survey was modelled after the National Cancer Institute's twenty-six-item Dietary Screener Questionnaire (DSQ) ${ }^{(31)}$, but also included less healthful entrées and convenience foods to better capture current trends in dietary behaviours among adolescents. Both parents ( $n$ 1848) and adolescents ( $n$ 1737) were asked about their intake frequency of foods and beverages during the past seven days including: green salad, non-fried vegetables, cooked beans, fruit, fried potatoes, other nonfried potatoes and $100 \%$ fruit juice. Response options ranged from 'did not consume in past 7 days', ' $1-3$ times in past 7 days', '4-6 times in past 7 days', ' 1 time per day', ' 2 times per day' to ' 3 or more times per day'. The complete wording of the dietary screener survey items can be found on the FLASHE study webpage (http://www.cancercontrol. cancer.gov/brp/hbrb/flashe.html).

\section{Daily intake}

To calculate daily intake frequencies of food and beverage groups, all responses were converted to daily frequency. For the response options ' $1-3$ times in the past 7 days' and '4-6 times in the past 7 days', the median was divided by 7 to equal 0.29 or 0.71 times/d, respectively. Also, the response option ' 3 or more times per day' was coded as 3 . Lastly, daily frequencies of several screener items that represented each food or beverage group were summed based upon existing studies that grouped particular food items together ${ }^{(17,32,33)}$. Participants without complete data for each food and beverage group were removed (adolescents, $n$ 24; adults, $n$ 13). A complete description of how frequencies were converted to $\mathrm{F} \& \mathrm{~V}$ cup equivalents can be found elsewhere ${ }^{(34)}$.

Estimated daily intake of dietary factors from FLASHE Dietary Screener items was based upon relationships detailed in the DSQ (e.g. fruit, fruit juice, salad, fried potatoes, other potatoes, dried beans, other vegetables, tomato sauce, salsa and pizza were used to estimate F\&V cup equivalents per day in the DSQ) ${ }^{(31)}$. Estimated intakes of cup equivalents of $\mathrm{F} \& \mathrm{~V}$ were calculated using SAS programs obtained from the Risk Factor Assessment Branch of the National Cancer Institute. The SAS programs were originally developed to compare the responses from the 2009-2010 National Health and Nutrition Examination Survey (NHANES) dietary screener (similar to the FLASHE Dietary Screener) with the What We Eat in America (WWEIA) $24 \mathrm{~h}$ dietary recall data from the 20032006 NHANES, and are described in detail elsewhere (https://epi.grants.cancer.gov/nhanes/dietscreen/scoring/ earlier/). The Risk Factor Assessment Branch has also most 
recently developed direct calibrations of 2009-2010 NHANES $24 \mathrm{~h}$ recall data to the DSQ, work that was published after conducting the current study ${ }^{(35)}$. The SAS programs for the current study were tailored by the National Cancer Institute's Risk Factor Assessment Branch to the FLASHE screener items. A detailed description of this methodology, including how the Risk Factor Assessment Branch estimated portion size and regression coefficients from the 2003-2006 NHANES data set, can be found elsewhere (https://epi.grants.cancer.gov/nhanes/ dietscreen/scoring/earlier/).

\section{Psychosocial factors and parent/caregiver factors}

Constructs and items for the FLASHE survey were selected based upon a conceptual model that can be found on the FLASHE study webpage (http://www.cancercontrol.cancer. gov/brp/hbrb/flashe.html). Several items were included in the FLASHE survey to address potential psychosocial correlates of FVI, as well as parent/caregiver factors associated with FVI among parents and adolescents. Response options for psychosocial variables were given across a 5-point Likert scale ( $1=$ 'strongly disagree' to $5=$ 'strongly agree'). Items included in the current analysis included the following for parents: (i) sociodemographic characteristics (sex (one item), age (one item), race/ethnicity (two items), income (one item), education (one item), marital status (one item)); (ii) psychosocial factors (autonomous motivation (two items), controlled motivation (two items), barriers (seven items), self-efficacy (one item), knowledge (one item), preferences for F\&V (two items)); and (iii) parenting factors (nine items). Items included in the current analysis included the following for adolescents: (i) sociodemographic characteristics (age (one item), sex (one item), race/ethnicity (two items)); (ii) psychosocial factors (autonomous motivation (two items), controlled motivation (two items), barriers (five items), self-efficacy (one item), knowledge (one item), preferences for F\&V (two items)); and (iii) parenting factors (nine items). Items are described in more detail elsewhere ${ }^{(36)}$ and the full survey wording and item sourcing is available on the FLASHE webpage. 'Autonomous' forms of motivation are those that reflect personal interests and values, whereas 'controlled' forms of motivation are those that reflect something one feels compelled to do by external or internal pressures ${ }^{(37)}$.

\section{Sociodemographic variables}

Parents reported age, sex, race/ethnicity, household income, their highest level of educational attainment and general health status. Adolescents reported their age, sex, race/ethnicity and general health status.

\section{Statistical approach}

All data analyses were conducted in the statistical software package SAS version 9.3. The unrestricted adolescent data set originally consisted of 1737 teens who were sampled in terms of demographics, of whom 1657 provided diet information and 1632 could have their intake frequencies/ amounts assessed; and after limiting it to complete observations, 805 of those remained. An adolescent observation was deemed complete if the adolescent had a valid response for each of the covariates used in the adolescent models for psychosocial factors and parent/ caregiver factors. The unrestricted parent/caregiver data set originally consisted of 1839 parents who were sampled in terms of demographics, of whom 1745 provided diet information and 1732 could have their intake frequencies/ amounts assessed; and after limiting it to complete observations, 1542 of those remained. Similar to the adolescent data set, a parent/caregiver observation was deemed complete if the parent/caregiver had a valid response for each of the covariates used in the parent/ caregiver models for psychosocial factors and parent/ caregiver factors. After excluding those without complete data, the analytic sample included 1542 parents and 805 adolescents.

To determine which variables influenced FVI, generalized linear models were utilized, using an $\alpha$ level of $0 \cdot 05$. Three separate models each using different sets of variables were run for both parents and adolescents, for a total of six models: (i) sociodemographic characteristics; (i) psychosocial factors; and (iii) parent/caregiver factors (i.e. home food environment). Only parents' sociodemographic characteristics were included in analyses, since adolescents did not report items such as income and education. Cup equivalents of F\&V were assessed separately for fruits and vegetables, but results were not unique enough to warrant reporting separately; thus only models using combined cups of F\&V as the dependent variable are reported below. In addition, to describe the characteristics of the sample more completely, we conducted Pearson correlations between BMI and FVI for both parents and teens as well as between parent and teen BMI.

\section{Results}

\section{Sample characteristics}

In total, we included 1542 adults living in the USA who completed the online survey and had complete data, along with 805 of their adolescents (aged 12-17.5 years). Adults were predominantly $35-59$ years old ( $86 \%$ ), female $(73 \%)$ and non-Hispanic White (71\%), followed by non-Hispanic Black (17\%), Hispanic (7\%), and other or multiple other races (5\%). In addition, adults generally reported an annual household income of less than \$US 100000 (79\%), $46 \%$ had earned a 4-year college degree or higher, and most were married (73\%). Half (50\%) of the adolescents ( $n$ 805) were aged $12-14$ years and were predominantly non-Hispanic White (66\%), followed by non-Hispanic Black (15\%), Hispanic (10\%), and other or multiple races (9\%; Table 1). For both parents and teens, as BMI increased, FVI tended to decrease $(r=-0.086$ and 
Table 1 Distribution of sociodemographics characteristics among parent $(n 1542)$ and adolescent $(n$ 805) respondents to the Family Life, Activity, Sun, Health, and Eating (FLASHE) survey, USA, April-October 2014

\begin{tabular}{|c|c|c|}
\hline Variable & $n$ & $\%$ \\
\hline \multicolumn{3}{|l|}{ Parents } \\
\hline \multicolumn{3}{|l|}{ Age } \\
\hline $18-34$ years & 173 & $11 \cdot 22$ \\
\hline $35-44$ years & 677 & 43.90 \\
\hline $45-59$ years & 645 & 41.83 \\
\hline$\geq 60$ years & 47 & 3.05 \\
\hline \multicolumn{3}{|l|}{ Sex } \\
\hline Male & 411 & 26.65 \\
\hline Female & 1131 & 73.35 \\
\hline \multicolumn{3}{|l|}{ Race } \\
\hline Hispanic & 110 & $7 \cdot 13$ \\
\hline Black only & 255 & $16 \cdot 54$ \\
\hline White only & 1095 & 71.01 \\
\hline Other & 82 & 5.32 \\
\hline \multicolumn{3}{|l|}{ Annual household income } \\
\hline \$US 0-99999 & 1223 & $79 \cdot 31$ \\
\hline$\geq \$$ US 100000 & 319 & $20 \cdot 69$ \\
\hline \multicolumn{3}{|l|}{ Highest level of education } \\
\hline Less than high school & 14 & 0.91 \\
\hline High school or GED & 270 & 17.51 \\
\hline Some college & 541 & 35.08 \\
\hline 4-year college degree or more & 717 & $46 \cdot 50$ \\
\hline \multicolumn{3}{|l|}{ Marital status } \\
\hline Married & 1126 & 73.02 \\
\hline Divorced, widowed or separated & 188 & $12 \cdot 19$ \\
\hline Never married & 141 & $9 \cdot 14$ \\
\hline Member of an unmarried couple & 87 & $5 \cdot 64$ \\
\hline \multicolumn{3}{|l|}{ Adolescents } \\
\hline \multicolumn{3}{|l|}{ Age } \\
\hline 12 years & 104 & $12 \cdot 92$ \\
\hline 13 years & 151 & $18 \cdot 76$ \\
\hline 14 years & 140 & $17 \cdot 39$ \\
\hline 15 years & 144 & 17.89 \\
\hline 16 years & 171 & $21 \cdot 24$ \\
\hline 17 years & 95 & 11.90 \\
\hline \multicolumn{3}{|l|}{ Sex } \\
\hline Male & 408 & $50 \cdot 68$ \\
\hline Female & 397 & $49 \cdot 32$ \\
\hline \multicolumn{3}{|l|}{ Race } \\
\hline Hispanic & 80 & 9.94 \\
\hline Black only & 124 & $15 \cdot 40$ \\
\hline White only & 530 & $65 \cdot 84$ \\
\hline Other & 71 & 8.82 \\
\hline
\end{tabular}

GED, General Educational Development.

$r=-0.096$ for parents and teens, respectively, both $P<0 \cdot 01)$. In addition, parent and teen BMI were positively correlated $(r=0.27, P<0.001)$.

\section{Fruit and vegetable intake}

Based on the algorithm used to convert frequency of intake to F\&V cup equivalents ${ }^{(35)}$, parents in the FLASHE sample were consuming 3.4 cup equivalents (males) and 2.7 cup equivalents (females; 2.9 cups for males and females combined), while both male and female adolescents were consuming $2 \cdot 2$ cup equivalents of $F \& V$ daily.

\section{Sociodemographic characteristics}

Educational attainment $\left(F_{(3,1470)}=8.39, P<0.001\right)$ and sex $\left(F_{(1,1470)}=101 \cdot 25, P<0 \cdot 001\right)$ were significant predictors of cups of FVI by parents and accounted for $8.8 \%$ of the
Table 2 Model 1: sociodemographic variables associated ${ }^{*}$ with fruit and vegetable intake among parent respondents $(n 1542)$ to the Family Life, Activity, Sun, Health, and Eating (FLASHE) survey, USA, April-October 2014

\begin{tabular}{lcccc}
\hline $\begin{array}{l}\text { Sociodemographic } \\
\text { variable }\end{array}$ & $\begin{array}{c}\text { Estimated } \\
\text { effect }\end{array}$ & SE & $t$ Value & $\operatorname{Pr}>|t|$ \\
\hline Sex & & & & \\
$\quad$ Male & 0.718 & 0.07 & 10.06 & $<0.0001$ \\
$\quad$ Female & Reference & - & - \\
Educational attainment & & & & \\
$\quad$ Less than high school & -0.445 & 0.39 & -1.15 & 0.2515 \\
$\quad$ High school or GED & -0.315 & 0.10 & -3.14 & 0.0017 \\
$\quad$ Some college & -0.372 & 0.08 & -4.61 & $<0.0001$ \\
$\quad$ 4-year college degree or & Reference & - & - \\
$\quad$ more & \multicolumn{5}{c}{} \\
\hline
\end{tabular}

GED, General Educational Development.

${ }^{*}$ We conducted a generalized linear model, using an a level of 0.05 .

variance (Table 2). Parents with higher levels of education reported eating more cups of $\mathrm{F} \& \mathrm{~V}$; when least-squares means were compared post hoc, it was found that participants with a 4-year degree or more consumed significantly more cups of $\mathrm{F} \& \mathrm{~V}$ than those with some college $(P<0 \cdot 001)$ or high school/General Educational Development $(P<0 \cdot 01)$. In addition, men (of any educational attainment) consumed on average 0.72 cups more of $F \& V$ daily than women.

\section{Psychosocial factors}

Table 3 shows that 'autonomous' and 'controlled motivation' were both significant correlates of cups of FVI by parents ('autonomous': $F_{(1,1468)}=18.50, P<0 \cdot 001$; 'controlled': $\left.\quad F_{(1,1468)}=52 \cdot 86, \quad P<0.001\right)$ and adolescents ('autonomous': $\quad F_{(1,758)}=10 \cdot 83, \quad P<0.001$; 'controlled': $\left.F_{(1,758)}=11.96, P<0.001\right)$. Barriers that were significant correlates for parental FVI included 'cost' $(P<0.001)$ and 'family not liking $\mathrm{F} \& \mathrm{~V}$ ' $(P<0 \cdot 05)$. In addition, 'self-efficacy for FVI' $(P<0.001)$ and 'preferences for fruit' $(P<0.001)$ were significant correlates of FVI among parents. For adolescents, 'not thinking of F\&V' $(P<0.001)$, 'not having F\&V packed in lunch' $(P<0.05)$, 'self-efficacy for FVI' $(P<0.001)$ and 'knowledge of $\mathrm{F} \& \mathrm{~V}$ recommendations' $(P<0.05)$ were significant correlates of F\&V cups consumed. Together, these psychosocial variables accounted for $19.03 \%$ of the variance in parents and $13.50 \%$ of the variance in teens. Respondents answered these psychosocial questions on a 5-point Likert scale ( $1=$ 'strongly disagree' to $5=$ 'strongly agree'). As reported in Table 4 , for parents, with every 1-point increase in Likert response for 'autonomous' and 'controlled motivation', 'self-efficacy' and 'preferences for fruit', there was a 0.209-0.277 increase in cups of FVI per day. Also among parents, for every 1-point increase in Likert response to barriers 'cost' and 'family not liking $\mathrm{F} \& \mathrm{~V}$ ', there was a $0 \cdot 105-0 \cdot 116$ decrease in cups of F\&V consumed daily. Similarly, among adolescents, for every 1-point increase in Likert response to 'autonomous' and 'controlled motivation', 'self-efficacy' and 'knowledge of $F \& V$ recommendations', there was a 
Table 3 Fruit and vegetable intake across psychosocial factor variables* among parent $(n 1542)$ and adolescent $(n 805)$ respondents to the Family Life, Activity, Sun, Health, and Eating (FLASHE) survey, USA, April-October 2014

\begin{tabular}{|c|c|c|c|c|}
\hline \multirow[b]{2}{*}{ Psychosocial factor } & \multicolumn{2}{|c|}{ Parent reported } & \multicolumn{2}{|c|}{ Adolescent reported } \\
\hline & $\begin{array}{l}\text { Mean } \\
\text { response }\end{array}$ & SD & $\begin{array}{l}\text { Mean } \\
\text { response }\end{array}$ & SD \\
\hline Autonomous motivation & $4 \cdot 31$ & 0.72 & 4.08 & 0.85 \\
\hline Controlled motivation & $2 \cdot 74$ & 0.96 & $3 \cdot 12$ & 1.06 \\
\hline \multicolumn{5}{|l|}{ Barriers to eating $F \& V$} \\
\hline Cost too much & $2 \cdot 88$ & 1.40 & - & - \\
\hline Time to prepare & 1.98 & 1.07 & - & - \\
\hline Family not like them & 2.04 & $1 \cdot 12$ & - & - \\
\hline Fruit has too much sugar & 2.09 & 1.08 & - & - \\
\hline Spoil before you can eat & $3 \cdot 11$ & 1.33 & 2.49 & 1.30 \\
\hline Not filling enough & $2 \cdot 37$ & 1.20 & $2 \cdot 64$ & 1.25 \\
\hline $\begin{array}{l}\text { Restaurant not serve } \\
\text { them }\end{array}$ & 2.05 & 1.08 & $2 \cdot 42$ & $1 \cdot 26$ \\
\hline Don't think of F\&V & - & - & 3.02 & 1.34 \\
\hline Not packed in lunch & - & - & $2 \cdot 21$ & 1.18 \\
\hline Self-efficacy for FVI & 4.02 & $1 \cdot 20$ & $4 \cdot 17$ & 1.01 \\
\hline $\begin{array}{l}\text { Knowledge of F\&V } \\
\text { recommendations }\end{array}$ & $3 \cdot 27$ & 3.72 & $4 \cdot 42$ & $2 \cdot 42$ \\
\hline Preferences for fruit & 4.65 & 0.69 & 4.42 & 0.87 \\
\hline Preferences for vegetables & 4.58 & 0.73 & 4.01 & 1.09 \\
\hline
\end{tabular}

$\mathrm{F} \& \mathrm{~V}$, fruits and vegetables; $\mathrm{FVI}$, fruit and vegetable intake.

*'-' indicates that this item was not assessed among parents or adolescents.

Table 4 Model 2: psychosocial factors associated ${ }^{*}$ with fruit and vegetable intake among parent $(n$ 1542) and adolescent $(n$ 805) respondents to the Family Life, Activity, Sun, Health, and Eating (FLASHE) survey, USA, April-October 2014

\begin{tabular}{lcccc}
\hline Psychosocial factor & $\begin{array}{c}\text { Estimated } \\
\text { effect }\end{array}$ & SE & $\begin{array}{c}t \\
\text { Value }\end{array}$ & $\operatorname{Pr}>|t|$ \\
\hline Parents & & & & \\
Autonomous motivation & 0.239 & 0.06 & 4.3 & $<0.0001$ \\
Controlled motivation & 0.277 & 0.04 & 7.27 & $<0.0001$ \\
Cost too much & -0.116 & 0.03 & -4.62 & $<0.0001$ \\
Family not like them & -0.105 & 0.03 & -3.27 & 0.0011 \\
Self-efficacy for FVI & 0.187 & 0.03 & 5.93 & $<0.0001$ \\
Preferences for fruit & 0.209 & 0.05 & 3.94 & $<0.0001$ \\
Adolescents & & & & \\
Autonomous motivation & 0.167 & 0.05 & 3.29 & 0.001 \\
Controlled motivation & 0.12 & 0.03 & 3.46 & 0.0006 \\
Don't think of F\&V & -0.115 & 0.03 & -3.99 & $<0.0001$ \\
Not packed in lunch & -0.093 & 0.03 & -2.94 & 0.0034 \\
Self-efficacy for FVI & 0.191 & 0.04 & 4.73 & $<0.0001$ \\
Knowledge of F\&V & 0.051 & 0.02 & 2.71 & 0.0069 \\
$\quad$ recommendations & & & & \\
\hline
\end{tabular}

FVI, fruit and vegetable intake; F\&V, fruits and vegetables.

*We conducted a generalized linear model, using an a level of 0.05.

0.051-0.191 increase in cups of FVI per day. In addition, adolescents reported barriers and for every 1-point increase in Likert response to 'not packed in lunch' and 'don't think of F\&V', there was a 0.093-0.115 decrease in cups of FVI (Table 4).

\section{Parent/caregiver factors}

Parenting factors were reported by both parents and adolescents, summarized in Table 5. "Parental role modelling of FVI' $\left(F_{(1,1474)}=16 \cdot 09, P<0 \cdot 001\right)$, 'deciding together with the
Table 5 Fruit and vegetable intake across parent/caregiver factors among parent $(n 1542)$ and adolescent $(n 805)$ respondents to the Family Life, Activity, Sun, Health, and Eating (FLASHE) survey, USA, April-October 2014

\begin{tabular}{|c|c|c|c|c|}
\hline \multirow[b]{2}{*}{ Parenting factor } & \multicolumn{2}{|c|}{ Parent reported } & \multicolumn{2}{|c|}{$\begin{array}{l}\text { Adolescent } \\
\text { reported }\end{array}$} \\
\hline & $\begin{array}{l}\text { Mean } \\
\text { response }\end{array}$ & SD & $\begin{array}{l}\text { Mean } \\
\text { response }\end{array}$ & SD \\
\hline $\begin{array}{l}\text { Cooking meals at home from } \\
\text { scratch }\end{array}$ & $4 \cdot 31$ & $2 \cdot 26$ & $4 \cdot 17$ & $2 \cdot 13$ \\
\hline Parent role models FVI & 4.14 & 0.95 & 4.23 & 0.99 \\
\hline $\begin{array}{l}\text { Make sure adolescent eats } \\
\text { enough F\&V }\end{array}$ & 3.92 & $1 \cdot 12$ & 3.51 & $1 \cdot 30$ \\
\hline Purchase F\&V for adolescent & 4.47 & 0.75 & 4.57 & 0.70 \\
\hline $\begin{array}{l}\text { Encourage adolescent to eat } \\
\text { different } F \& V\end{array}$ & 4.45 & 0.73 & 4.49 & 0.77 \\
\hline $\begin{array}{l}\text { Decide together how many F\&V } \\
\text { adolescent eats }\end{array}$ & 3.14 & $1 \cdot 22$ & $3 \cdot 23$ & 1.29 \\
\hline Make adolescent eat F\&V & 3.35 & 1.28 & 3.45 & 1.33 \\
\hline $\begin{array}{l}\text { Make rules about how many } \\
\text { F\&V adolescent eats }\end{array}$ & 3.85 & 1.06 & 3.66 & $1 \cdot 13$ \\
\hline Have F\&V available in the home & 4.35 & 0.83 & 4.35 & 0.86 \\
\hline
\end{tabular}

$\mathrm{FVI}$, fruit and vegetable intake; F\&V, fruits and vegetables.

adolescent how many $\mathrm{F} \& \mathrm{~V}$ the adolescent should eat' $\left(F_{(1,1474)}=26 \cdot 66, P<0.001\right)$ and 'having $\mathrm{F} \& \mathrm{~V}$ available in the home' $\left(F_{(1,1474)}=128.83, P<0.001\right)$ were significant correlates of cups of FVI for parents and accounted for $15.6 \%$ of the variance. For adolescents, the 'number of days meals are cooked at home from scratch' $\left(F_{(1,764)}=3.90, P<0.05\right)$, 'parent purchases F\&V' $\left(F_{(1,764)}=8.43, P<0.01\right)$, 'deciding together with the parent how many $\mathrm{F} \& \mathrm{~V}$ the adolescent should eat' $\left(F_{(1,764)}=18.99, P<0.001\right)$, 'parent making rules about how many F\&V the adolescent should eat' $\left.F_{(1,764)}=8.20, P<0.01\right)$ and having $\mathrm{F} \& \mathrm{~V}$ available in the home' $\left(F_{(1,764)}=6.51, P<0.05\right)$ were significant correlates of cups of FVI and accounted for $13.6 \%$ of the variance. Respondents answered these parent/caregiver questions on a 5-point Likert scale ( $1=$ 'strongly disagree' to $5=$ 'strongly agree'). Among parents, with every 1-point increase in Likert response for 'role modeling', 'deciding how many F\&V together' and 'having F\&V available in the home', there was a 0.159-0.509 increase in cups of FVI (Table 6). Among adolescents, with every 1-point increase in Likert response for 'cooking meals at home', 'purchases F\&V, 'deciding how many F\&V together', 'parental rules about how many $\mathrm{F} \& \mathrm{~V}$ adolescent eats' and 'having F\&V available in the home', there was a $0 \cdot 035-0 \cdot 184$ increase in cups of FVI (Table 6).

\section{Discussion}

The focus of the present study was to examine the correlates of FVI among parents and their adolescent offspring. Adult participants in the FLASHE survey reported consuming $3 \cdot 4$ cups (males) and $2 \cdot 7$ cups (females) of F\&V daily. Another study using a nationally representative 
Table 6 Model 3: parent/caregiver factors associated ${ }^{*}$ with fruit and vegetable intake among parent $(n$ 1542) and adolescent $(n$ 805) respondents to the Family Life, Activity, Sun, Health, and Eating (FLASHE) survey, USA, April-October 2014

\begin{tabular}{|c|c|c|c|c|}
\hline Parent/caregiver factor & $\begin{array}{l}\text { Estimated } \\
\text { effect }\end{array}$ & SE & $\begin{array}{c}t \\
\text { Value }\end{array}$ & $\operatorname{Pr}>|t|$ \\
\hline \multicolumn{5}{|l|}{ Parents } \\
\hline Parent role models FVI & 0.168 & 0.04 & 4.01 & $<0.0001$ \\
\hline $\begin{array}{l}\text { Decide together how many } \\
\text { F\&V adolescent eats }\end{array}$ & $0 \cdot 159$ & 0.03 & $5 \cdot 16$ & $<0.0001$ \\
\hline $\begin{array}{l}\text { Have F\&V available in the } \\
\text { home }\end{array}$ & 0.509 & 0.04 & 11.35 & $<0.0001$ \\
\hline \multicolumn{5}{|l|}{ Adolescents } \\
\hline $\begin{array}{l}\text { Cooking meals at home from } \\
\text { scratch }\end{array}$ & 0.035 & 0.02 & 1.98 & 0.0486 \\
\hline $\begin{array}{l}\text { Purchase F\&V for } \\
\text { adolescent }\end{array}$ & $0 \cdot 184$ & 0.06 & $2 \cdot 9$ & 0.0038 \\
\hline $\begin{array}{l}\text { Decide together how many } \\
\text { F\&V adolescent eats }\end{array}$ & 0.137 & 0.03 & 4.36 & $<0.0001$ \\
\hline $\begin{array}{l}\text { Make rules about how many } \\
\mathrm{F} \& \mathrm{~V} \text { adolescent eats }\end{array}$ & 0.104 & 0.04 & $2 \cdot 86$ & 0.0043 \\
\hline $\begin{array}{l}\text { Have F\&V available in the } \\
\text { home }\end{array}$ & 0.128 & 0.05 & 2.55 & 0.0109 \\
\hline
\end{tabular}

FVI, fruit and vegetable intake; F\&V, fruits and vegetables.

*We conducted a generalized linear model, using an a level of 0.05.

sample of adults from 2009-2010 revealed lower intakes for males at $2 \cdot 81 \mathrm{~F} \& \mathrm{~V}$ cup equivalents daily and 2.52 cup equivalents among females ${ }^{(38)}$. Assessing FVI is an everevolving science that faces several challenges including response bias, varied methods across studies, high respondent burden, and limited validity and reliability of existing measurement methods ${ }^{(39)}$. Adolescents in our study reported $2 \cdot 2$ cups of $F \& V$ daily (both male and female), compared with $2 \cdot 10$ and 1.98 cup equivalents of $\mathrm{F} \& \mathrm{~V}$ in males and females, respectively, in the aforementioned nationally representative study ${ }^{(38)}$. Although somewhat higher than other national data, FVI in our study still fell below the recommendations for daily intake (4-4.5 cups) according to the 2015 Dietary Guidelines for Americans ${ }^{(40,41)}$. Given the ongoing concern of insufficient FVI among Americans ${ }^{(42)}$, it is important to understand factors that influence this trend. Previous studies have presented mixed results in terms of FVI among men and women. A few studies have demonstrated that women tend to consume more F\&V than men ${ }^{(43-45)}$ and that men's intake has declined at a more rapid pace than women's ${ }^{(46)}$. However, in another study with a nationally representative sample, men consumed 0.71 more daily servings of $F \& V$ than women ${ }^{(47)}$. Our data also demonstrated that men reported greater FVI than women. Perhaps this is because men typically consume more energy overall, and therefore report a larger amount of $\mathrm{F} \& \mathrm{~V}$ also. In addition, parents with higher educational attainment reported eating more cups of $\mathrm{F} \& \mathrm{~V}$, aligning with a body of supportive evidence $^{(48,49)}$.

Both autonomous and controlled motivation items were correlates of FVI in the current study, with respondents reporting greater agreement with statements about why they eat F\&V also reporting greater FVI. As described above, autonomous motivation includes personal interests and values, whereas controlled motivation reflects something one feels compelled to do by external or internal pressures $^{(37)}$. Typically, autonomous forms of motivation are generally more effective in predicting health behavior than non-self-determined or controlled forms ${ }^{(37)}$. A previous study using FLASHE data demonstrated that an individual's autonomous motivation was correlated with his/her own FVI among parents and adolescents, and also that of their matching parent-adolescent FVI using a dyadic analytic approach ${ }^{(50)}$. In the current study, the strength of the relationship of controlled motivation was stronger than autonomous (i.e. larger $F$ value). Perhaps this somewhat contradictory finding compared with the other FLASHE study is due to only having two items for each autonomous motivation and controlled motivation, while the full validated instrument includes fifteen items ${ }^{(51)}$. These results support suggestions that tailoring messaging and interventions to the type of motivation preferred (autonomous or controlled) can enhance the impact of outcomes ${ }^{(52)}$.

Some items assessing barriers for FVI were different for parents and adolescents, hence parents reported cost and their family not liking F\&V as significant barriers for their own FVI. Perceived high cost is often cited as a barrier to FVI, particularly among low-income populations ${ }^{(53,54)}$. Healthy food incentive programmes ${ }^{(55)}$, subsidies to strengthen the supply chain for $F \& V^{(56,57)}$ and nutrition and cooking education ${ }^{(22,58)}$ remain important strategies to increase population levels of FVI. The FLASHE sample did not include an oversampling of lower-income households (i.e. $24 \%$ of households reported annual income $\leq \$ \mathrm{US}$ $34999^{(34)}$ ), yet cost remained an important issue for a wider range of income. In addition, self-efficacy for FVI for both parents and their adolescent was identified as a significant correlate of FVI, which is not surprising given the robustness of self-efficacy as a significant psychosocial correlate in many studies and the prevalence of including measurement of self-efficacy ${ }^{(59-61)}$.

Parental and home environment factors were also significant correlates of FVI for both parents and adolescents. The importance of the home environment in setting the stage for the development of important health behaviours among children is widely accepted ${ }^{(26,27)}$. From the parents' perspective in our study, fostering FVI among their children seems to revolve around providing a supportive environment, and not dictating, since parental FVI (i.e. role modelling) was predicted by deciding together how much F\&V adolescents should consume and providing F\&V to be available in the home. These echo previous findings showing that authoritative parenting style that parents received to be impactful on their own $\mathrm{FVI}^{(62)}$. Our study also demonstrated that meals cooked at home and parents buying $\mathrm{F} \& \mathrm{~V}$ and having them available in the home were significant correlates of adolescents' FVI. These factors are representative of an 'authoritative' 
parenting style that is high in warmth and expectations for the adolescent's FVI, which has demonstrated a positive impact on children's dietary behaviour ${ }^{(62)}$. From the adolescents' perspective, deciding how many F\&V they should consume together with their parents was also a significant correlate of their FVI. A previous FLASHE study used actorindependence models and structural equation modelling with parent-child dyads and found that emotion suppression reduces FVI and increases intake of hedonic foods, suggesting emotion regulation as a potential behavioural target for health promotion ${ }^{(63)}$. In addition, a significant correlate of adolescents' FVI also included parents making rules about how much F\&V adolescents should eat. Providing rules for children in terms of dietary behaviours has demonstrated a positive effect on the resultant child dietary behaviour in other studies ${ }^{(64)}$. These parenting factors should be explored further from a dyadic perspective, as teen-reported role modelling was included in the survey but it did not remain significant in the final models. Teens may be unaware of their parents' efforts to role model positive dietary behaviours, yet still benefit from a home food environment that provides F\&V options.

A few limitations of the current study require acknowledgement. Data collected for the FLASHE survey were selfreported; therefore, there may be potentially biased responses. Further, the sample was drawn using a consumer opinion panel and not a random sample, although similar data collection techniques have been used in other large health behavior surveys (e.g. the National Cancer Institute's Food Attitudes and Behaviors Survey and the Centers for Disease Control and Prevention's Styles surveys). For the purpose of the present paper, we did not analyse parents and adolescents as dyads, but rather as two unique groups, which limits interpretation to parents and adolescents separately. Several of the variables of interest for the current paper were not the same between parents and adolescents, limiting the ability to conduct a true dyadic analysis. In dyadic analysis the actor-partner interdependence model is reciprocal, meaning that both members of the dyad have a score for each variable ${ }^{(65,66)}$. In addition, beyond FVI, we acknowledge that dietary patterns are influenced across multiple food categories, which is described comprehensively in a previous paper ${ }^{(34)}$. Furthermore, excluding about half of the non-responding adolescents from the analysis is another limitation. Finally, the study was exploratory and we did not have any a priori hypotheses to test, but rather sought to identify significant factors for FVI among parents and adolescents in a national sample.

Despite these limitations, a number of implications can be gleaned from the present study. The algorithms developed and used to estimate dietary consumption for the current study were built from the DSQ, utilizing the best science available and NHANES $24 \mathrm{~h}$ recall data to calculate cup equivalents of $F \& V^{(34)}$. This methodology used for the FLASHE Dietary Screener is short and feasible, balanced with the added rigour and robustness of using NHANES data to yield estimates for the amount of particular food groups consumed. This detailed report of parents' and their adolescents' FVI, and the factors across the social-ecological model that influence this behaviour, can be utilized to inform intervention and nutrition education efforts. Researchers and public health professionals may want to consider tailored approaches for increasing FVI in a variety of settings across different populations ${ }^{(67)}$. In addition, the present study emphasizes the importance of the role of parent behaviour in the home as a correlate for FV intake for adolescents. Future study in this area should extend beyond cross-sectional designs and attempt some longitudinal research designs, which would allow for the examination of how the family dynamic and home environment influence FVI over time.

Overall, these findings point to specific factors that impact FVI among parents and their adolescent(s). Particular consideration to prominent factors, such as different forms of motivation, self-efficacy and parental/home environment factors, may enhance intervention approaches. Looking beyond individually oriented approaches to focus on variables across the social-ecological model may also be beneficial ${ }^{(68)}$. The current findings underscore the importance of considerations of individual differences and their settings, and ways in which health promotion efforts can be enhanced for effectiveness.

\section{Acknowledgements}

Financial support: FLASHE was funded with federal funds from the National Cancer Institute, National Institutes of Health (NIH), under contract number HHSN261201200039I issued to Westat, Inc. The funder had no role in the design, analysis or writing of this article. Conflict of interest: None. Authorship: C.A.P., T.M.S., E.E.C., A.Y.O., L.A.D. and A.L.Y. contributed to the conceptualization of the research question and analysis plan. A.Y.O., L.C.N. and A.L.Y. helped lead the development of the FLASHE survey tool and oversaw data collection. C.A.P. drafted the initial manuscript. C.B. performed the analyses and drafted the statistical section of the initial manuscript. All authors revised the manuscript for important intellectual content, approved the final version to be published and agree to be accountable of all aspects of the work. Etbics of human subject participation: This study was conducted according to the guidelines laid down in the Declaration of Helsinki and all procedures involving human subjects were approved by the institutional review boards of the NIH and the main contractor, Westat, Inc. Written informed consent was obtained from all subjects.

\section{References}

1. Ogden CL, Carroll MD, Kit BK et al. (2014) Prevalence of childhood and adult obesity in the United States, 2011-2012. JAMA 311, 806-814.

2. Dixon JB (2010) The effect of obesity on health outcomes. Mol Cell Endocrinol 316, 104-108. 
3. Hammond RA \& Levine R (2010) The economic impact of obesity in the United States. Diabetes Metab Syndr Obes $\mathbf{3}$, 285-295.

4. Thorpe KE, Florence CS, Howard DH et al. (2004) The impact of obesity on rising medical spending. Health Aff (Millwood) 23, 283-283.

5. Wardle J \& Cooke L (2005) The impact of obesity on psychological well-being. Best Pract Res Clin Endocrinol Metab 19, 421-440.

6. Gross LS, Li L, Ford ES et al. (2004) Increased consumption of refined carbohydrates and the epidemic of type 2 diabetes in the United States: an ecologic assessment. Am J Clin Nutr 79, 774-779.

7. Young LR \& Nestle M (2002) The contribution of expanding portion sizes to the US obesity epidemic. Am J Public Health 92, 246-249.

8. Drewnowski A (2004) Obesity and the food environment: dietary energy density and diet costs. Am J Prev Med 27, 154-162.

9. Drewnowski A \& Specter S (2004) Poverty and obesity: the role of energy density and energy costs. Am J Clin Nutr 79, 6-16.

10. Field AE, Gillman MW, Rosner B et al. (2003) Association between fruit and vegetable intake and change in body mass index among a large sample of children and adolescents in the United States. Int J Obes Relat Metab Disord 27, 821-826.

11. Michimi A \& Wimberly MC (2010) Associations of supermarket accessibility with obesity and fruit and vegetable consumption in the conterminous United States. Int J Health Geogr 9, 49.

12. Panagiotakos DB, Chrysohoou C, Pitsavos C et al. (2006) Association between the prevalence of obesity and adherence to the Mediterranean diet: the ATTICA study. Nutrition 22, 449-456.

13. Togo P, Osler M, Sørensen T et al. (2004) A longitudinal study of food intake patterns and obesity in adult Danish men and women. Int J Obes Relat Metab Disord 28, 583-593.

14. Wang Y, Ge K \& Popkin BM (2003) Why do some overweight children remain overweight, whereas others do not? Public Health Nutr 6, 549-558.

15. Cohen JH, Kristal AR \& Stanford JL (2000) Fruit and vegetable intakes and prostate cancer risk. J Natl Cancer Inst 92, 61-68.

16. Hung HC, Joshipura KJ, Jiang R et al. (2004) Fruit and vegetable intake and risk of major chronic disease. $J$ Natl Cancer Inst 96, 1577-1584.

17. Centers for Disease Control and Prevention (2011) Fruit and vegetable consumption among high school students United States, 2010. MMWR Morb Mortal Wkly Rep 60, $1583-1586$

18. Guenther PM, Dodd KW, Reedy J et al. (2006) Most Americans eat much less than recommended amounts of fruits and vegetables. J Am Diet Assoc 106, 1371-1379.

19. Ho SY, Wong BYM, Lo WS et al. (2010) Neighbourhood food environment and dietary intakes in adolescents: sex and perceived family affluence as moderators. Int J Pediatr Obes 5, 420-427.

20. Williams L, Ball K \& Crawford D (2010) Why do some socioeconomically disadvantaged women eat better than others? An investigation of the personal, social and environmental correlates of fruit and vegetable consumption. Appetite 55, 441-446.

21. Guillaumie L, Godin G \& Vézina-Im LA (2010) Psychosocial determinants of fruit and vegetable intake in adult population: a systematic review. Int J Behav Nutr Phys Act 7, 12.

22. Shaikh AR, Yaroch AL, Nebeling L et al. (2008) Psychosocial predictors of fruit and vegetable consumption in adults: a review of the literature. Am J Prev Med 34, 535-543.

23. De Bourdeaudhuij I, te Velde S, Brug J et al. (2007) Personal, social and environmental predictors of daily fruit and vegetable intake in 11-year-old children in nine European countries. Eur J Clin Nutr 62, 834-841.
24. Neumark-Sztainer D, Wall M, Perry C et al. (2003) Correlates of fruit and vegetable intake among adolescents: findings from Project EAT. Prev Med 37, 198-208.

25. Odum M, Houseman JM, Williams RD et al. (2016) Predicting US adolescent fruit and vegetable consumption: which socioecological factors matter? Am J Health Stud 31, 213-221.

26. McClain AD, Chappuis C, Nguyen-Rodriguez ST et al. (2009) Psychosocial correlates of eating behavior in children and adolescents: a review. Int J Behav Nutr Phys Act 6, 54.

27. Pearson N, Biddle SJ \& Gorely T (2009) Family correlates of fruit and vegetable consumption in children and adolescents: a systematic review. Public Health Nutr 12, 267-283.

28. Golan M \& Crow S (2004) Parents are key players in the prevention and treatment of weight-related problems. Nutr Rev 62, 39-50.

29. Rosenkranz RR \& Dzewaltowski DA (2008) Model of the home food environment pertaining to childhood obesity. Nutr Rev 66, 123-140.

30. Oh AY, Davis T, Dwyer LA et al. (2017) Recruitment, enrollment, and response of parent-adolescent dyads in the FLASHE Study. Am J Prev Med 52, 849-855.

31. National Cancer Institute \& Applied Research Cancer Control and Population Sciences (2014) Dietary Screener Questionnaire in the NHANES 2009-10: Background. http:// appliedresearch.cancer.gov/nhanes/dietscreen/ (accessed April 2014).

32. Montoye AH, Pfeiffer KA, Alaimo K et al. (2013) Junk food consumption and screen time: association with childhood adiposity. Am J Health Behav 37, 395-403.

33. Perrine CG, Galuska DA, Thompson FE et al. (2014) Breastfeeding duration is associated with child diet at 6 years. Pediatrics 134, Suppl. 1, S50-S55.

34. Smith TM, Calloway EE, Pinard CA et al. (2017) Using secondary 24-hour dietary recall data to estimate daily dietary factor intake from the FLASHE study dietary screener. $A m J$ Prev Med 52, 856-862.

35. Thompson FE, Midthune D, Kahle L et al. (2017) Development and evaluation of the National Cancer Institute's dietary screener questionnaire scoring algorithms. I Nutr 147, 1226-1233.

36. Nebeling LC, Hennessy E, Oh AY et al. (2017) The FLASHE study: survey development, dyadic perspectives, and participant characteristics. Am J Prev Med 52, 839-848.

37. Hagger MS, Hardcastle SJ, Chater A et al. (2014) Autonomous and controlled motivational regulations for multiple health-related behaviors: between- and within-participants analyses. Health Psychol Behav Med 2, 565-601.

38. US Department of Agriculture (2010) Mean Daily Food Patterns Cup Equivalents Consumed Per Individual, by Gender and Age, in the United States, 2009-2010. http://www.ars.usda.gov/ARSUserFiles/80400530/pdf/fped/ table_1_fped_gen_0910.pdf (accessed August 2017).

39. Yaroch AL, Tooze J, Thompson FE et al. (2012) Evaluation of three short dietary instruments to assess fruit and vegetable intake: the National Cancer Institute's Food Attitudes and Behaviors (FAB) survey. J Acad Nutr Diet 112, 1570-1577.

40. US Department of Agriculture (2012) Choose MyPlate. http://www.choosemyplate.gov (accessed July 2012).

41. US Department of Health and Human Services \& US Department of Agriculture (2015) 2015-2020 Dietary Guidelines for Americans, 8th ed. Washington, DC: US Government Printing Office; available at http://health.gov/ dietaryguidelines/2015/guidelines/

42. Moore LV \& Thompson FE (2015) Adults meeting fruit and vegetable intake recommendations - United States, 2013. MMWR Morb Mortal Wkly Rep 64, 709-713.

43. Bélanger M, Poirier M, Jbilou J et al. (2014) Modelling the impact of compliance with dietary recommendations on cancer and cardiovascular disease mortality in Canada. Public Health 128, 222-230. 
44. Grimm KA, Foltz JL, Blanck HM et al. (2012) Household income disparities in fruit and vegetable consumption by state and territory: results of the 2009 Behavioral Risk Factor Surveillance System. J Acad Nutr Diet 112, 2014-2021.

45. Imamura F, Micha R, Khatibzadeh S et al. (2015) Dietary quality among men and women in 187 countries in 1990 and 2010: a systematic assessment. Lancet Glob Health 3, e132-e142.

46. Blanck HM, Gillespie C, Kimmons JE et al. (2008) Trends in fruit and vegetable consumption among US men and women, 1994-2005. Prev Chronic Dis 5, A35.

47. Dubowitz T, Heron M, Bird CE et al. (2008) Neighborhood socioeconomic status and fruit and vegetable intake among whites, blacks, and Mexican Americans in the United States. Am J Clin Nutr 87, 1883-1891.

48. Ball K, Crawford D \& Mishra G (2006) Socio-economic inequalities in women's fruit and vegetable intakes: a multilevel study of individual, social and environmental mediators. Public Health Nutr 9, 623-630.

49. Casagrande SS, Wang Y, Anderson C et al. (2007) Have Americans increased their fruit and vegetable intake? the trends between 1988 and 2002. Am J Prev Med 32, 257-263.

50. Dwyer LA, Bolger N, Laurenceau JP et al. (2017) Autonomous motivation and fruit/vegetable intake in parentadolescent dyads. Am J Prev Med 52, 863-871.

51. Levesque CS, Williams GC, Elliot D et al. (2007) Validating the theoretical structure of the Treatment Self-Regulation Questionnaire (TSRQ) across three different health behaviors. Health Educ Res 22, 691-702.

52. Resnicow K, Davis RE, Zhang G et al. (2008) Tailoring a fruit and vegetable intervention on novel motivational constructs: results of a randomized study. Ann Behav Med 35, 159-169.

53. Chuan Ling AM \& Horwath C (2001) Perceived benefits and barriers of increased fruit and vegetable consumption: validation of a decisional balance scale. J Nutr Educ 33, 257-265.

54. Yeh MC, Ickes SB, Lowenstein LM et al. (2008) Understanding barriers and facilitators of fruit and vegetable consumption among a diverse multi-ethnic population in the USA. Health Promot Int 23, 42-51.
55. An R (2013) Effectiveness of subsidies in promoting healthy food purchases and consumption: a review of field experiments. Public Health Nutr 16, 1215-1228.

56. Fields S (2004) The fat of the land: do agricultural subsides foster poor health? Environ Health Perspect 112, A820-A823.

57. Franck C, Grandi SM \& Eisenberg MJ (2013) Agricultural subsidies and the American obesity epidemic. Am J Prev Med 45, 327-333.

58. Ammerman AS, Lindquist $\mathrm{CH}$, Lohr $\mathrm{KN}$ et al. (2002) The efficacy of behavioral interventions to modify dietary fat and fruit and vegetable intake: a review of the evidence. Prev Med 35, 25-41.

59. AbuSabha R \& Achterberg C (1997) Review of self-efficacy and locus of control for nutrition-and health-related behavior. J Am Diet Assoc 97, 1122-1132.

60. Schwarzer R (2008) Modeling health behavior change: how to predict and modify the adoption and maintenance of health behaviors. Appl Psychol 57, 1-29.

61. Schwarzer R (editor) (2014) Self-Efficacy: Thought Control of Action. Abingdon: Routledge.

62. Blissett J (2011) Relationships between parenting style, feeding style and feeding practices and fruit and vegetable consumption in early childhood. Appetite 57, 826-831.

63. Ferrer RA, Green PA, Oh AY et al. (2017) Emotion suppression, emotional eating, and eating behavior among parent-adolescent dyads. Emotion 17, 1052-1065.

64. Verloigne M, Van Lippevelde W, Maes L et al. (2013) Family-and school-based predictors of energy balancerelated behaviours in children: a 6-year longitudinal study. Public Health Nutr 16, 202-211.

65. Reed RG, Butler EA \& Kenny DA (2013) Dyadic models for the study of health. Soc Personal Psychol Compass 7, $228-245$.

66. Kenny DA \& Cook W (1999) Partner effects in relationship research: conceptual issues, analytic difficulties, and illustrations. Pers Relatsh 6, 443-448.

67. Noar SM, Benac CN \& Harris MS (2007) Does tailoring matter? Meta-analytic review of tailored print health behavior change interventions. Psychol Bull 133, 673-693.

68. Golden SD \& Earp JAL (2012) Social ecological approaches to individuals and their contexts: twenty years of health education \& behavior health promotion interventions. Health Educ Behav 39, 364-372. 